\title{
Study on the Innovation and Entrepreneurship Curriculum System for Graduates Based on Extenics
}

\author{
Jiang Fan \\ School of Mechanical and Electrical Engineering, \\ Guangzhou University \\ Guangzhou, China \\ Jiangfan2008@gzhu.edu.cn
}

\begin{abstract}
To solve the difficult problem in the construction of the innovation and entrepreneurship curriculum system for graduate students by use of Extenics innovation method, this paper builds the curriculum system of innovative ability for graduate students with "a goal of curriculum, three systems, and one support". A training goal is that with innovation knowledge, innovation quality and innovation ability; three systems with interacting mean the innovation curriculum system, the innovation practice system, and the continuous improvement system; the support is Extenics, indicating that Extenics innovation method is integrated with major core curriculums, and the research teaching method is integrated with CDIO teaching principle.
\end{abstract}

Keywords-Innovation and entrepreneurship; Graduate students; Curriculum system; Extenics innovation method

\section{INTRODUCTION}

Graduate innovative education has always been a major concern of education in the world, and the curriculum system construction is key point to the graduate innovative training.

$\mathrm{Hu}$ et al proposed, the university has set up a scientific and systematic "education curriculum group", including the setting up of the required courses for the general education of entrepreneurship education in the training program, the elective course of professional education, and the implementation of the graduate innovation research program [1]. Zhang et al thought universities should set up a curriculum system of entrepreneurship education adapted to students' needs, and strengthen entrepreneurship education and knowledge imparting [2]. Hu et al have constructed a hierarchical and organic connection curriculum system of innovation and entrepreneurship in universities [3]. Li proposed a 16-course, 4-module curriculum, featuring aspiration cultivation, opportunity identification, startup establishment, and enterprise organization and management based on the general law in the process of entrepreneurship and the differences among disciplines [4]. Jiang et al used the creative method to improve the innovation ability training [513]. However, there are some problems about curriculum construction in postgraduate innovative education, such as the negative influence of traditional educational thoughts on Creative Education, the lack of innovation environment, some defects of existing curriculum system, etc. This paper

\author{
Chen Jiangdong, Xiao Zhongmin, Wu Qingfeng, Liu \\ Zhenzhang \\ School of Mechanical and Electrical Engineering, \\ Guangzhou University \\ Guangzhou, China
}

introduces Extenics to the cultivation of graduates' innovation ability, solve the difficult problems of the cultivation of graduates' innovation ability. Moreover, the curriculum system of cultivating postgraduates' innovative ability is established.

\section{THE SOLUTION OF THE CURRICULUM CONSTRUCTION PROBLEM FOR GRADUATE STUDENTS IN MECHANICAL ENGINEERING}

\section{A. Extenics innovation method}

The method of Extenics innovation consists of four steps: modeling, expanding, transforming and selecting. Extenics formalization model is the basis of analysis of Extenics, including matter-element, affair-element and relation-element model, also known as the element model, is made up of the triple of objects, features and value, and the commonly used forms are matrices or tables.

The matter-element is used to describe the "object", which represents the triple of the name, character, and magnitude of the object. To describe a graduate, the mater element is showed in table 1.

\begin{tabular}{c|c|c}
\multicolumn{2}{c}{ TABLE I } & DESCRIPTION OF MATTER-ELEMENT \\
\hline Matter & Features & Magnitude \\
\hline $\begin{array}{c}\text { Graduate student } \\
\text { D }\end{array}$ & Gender & Female \\
\cline { 2 - 3 } & Age & 24 \\
\cline { 2 - 3 } & $\ldots$ & $\ldots$ \\
\hline
\end{tabular}

\footnotetext{
Affair-element is used to describe "action", which is expressed as the triple of "verb, characteristic, quantity". Different from matter-element, the feature of affair- element is relatively definite. The commonly used feature is the object of action, accepted object, dominant object, time, place, tools and so on. The relation-element is used to describe the relationship between matters and matters, affairs and affairs, or between matters and affairs, and represents the triple of "relationship words, features, and values". The features of the relationelements are also relatively certain, and the commonly used items are: preceding item, latter item, degree, maintenance ways, contact information, contact channel, location, etc.
} 
The extension analysis is to expand the analysis of the objects (matters, affairs, relation) of the primitive model, including divergence tree, division chain, correlation network, implication system and so on. Table 2 gives an example of divergent tree analysis of teaching affair element.

TABLE II THE DIVERGENT TREE EXTENSION OF AFFAIR-ELEMENT

\begin{tabular}{|c|c|c|c|}
\hline Verb & Feature & Magnitude & Magnitude extension \\
\hline \multirow[t]{3}{*}{ Guide } & Object of action & Teacher D4 & Teacher D2,... \\
\hline & Accepted object & Student D5 & Student D3,... \\
\hline & Dominant object & project E2 & Curriculum D6,... \\
\hline Verb extension & Feature expansion & Magnitude & Magnitude expansion \\
\hline Cooperate & Degree & Tough & Loose,$\ldots$ \\
\hline$\ldots$ & $\ldots$ & $\ldots$ & $\ldots$ \\
\hline
\end{tabular}

The extension transform transforms the various ways of the expansion analysis into the feasible scheme, including the basic transform (replacement, add or delete, expansion and shrinking, decomposition, replication), conversion of operation, conduction transformation, etc. Table 3 shows an example of increasing the relationship between teachers and students.

TABLE III ADDITION TRANSFORMATIONS OF RELATIONAL ELEMENTS

\begin{tabular}{|c|c|c|c|c|c|}
\hline \multicolumn{3}{|c|}{ Before transformation } & \multicolumn{3}{|c|}{ After transformation } \\
\hline Object & Features & Magnitude & Object & Features & Magnitude \\
\hline \multirow{3}{*}{$\begin{array}{l}\text { Teacher-student } \\
\text { relationship }\end{array}$} & Preceding item & Teacher D4 & \multirow{3}{*}{$\begin{array}{l}\text { Teacher-student } \\
\text { relationship }\end{array}$} & Preceding item & Teacher D4 \\
\hline & The latter item & Student D5 & & The latter item & Student D5 $\oplus$ Student D6 \\
\hline & $\cdots$ & $\cdots$ & & $\cdots$ & $\cdots$ \\
\hline
\end{tabular}

Project selection is to select generated innovative solutions through transformation according to the experience. For the complex problem, Extenics provides the superiority evaluation method, which is to determine the index weights in the selection, correlation function, calculated for each scheme based on correlation degree in standardization, according to the optimization value of scheme.

\section{B. Difficulties of curriculum system construction in the graduate innovation education}

Through the study of teachers and students and literature review of the paper, we found that there are some difficult problems in innovation education of mechanical professional postgraduate in local university.

The curriculum system for innovation and entrepreneurship has not been established. 2) Lack of pertinence in the design of innovative and entrepreneurial curriculum. 3) The curriculum system of innovation and entrepreneurship has not been integrated with professional education.

\section{The extenics solution of the contruction problem of curriculum system for innovation education}

Through the analysis of difficulty of curriculum system in the innovation of education for graduate students of mechanical engineering in local universities, a solution was established to solve this problem.

The method of extension solution is based on the problem modeling, which is to expand the analysis, Extenics transformation, optimal plan, and scheme selection.

\section{THE TEACHING METHOD OF INNOVATIVE-IMPROVED} TOOLS

By imparting extension innovative tools, the innovation ability of graduate students can be improved. Through the study, we find that there are two approaches can be used to improve the efficiency of innovation tools impartment [10-13] First, the teaching of extension innovative tools should be combined with the professional technology and the cases around them so as to achieve the learning effect. For example, in the course of mechanism analysis and comprehensive, when applying divergent tree method to analyze the Mechanism scheme of transforming circular motion into linear motion, crank mechanism, the gear rack mechanism, the cam mechanism, the ball screw mechanism, the sine mechanism, the chain drive and the belt drive can be obtained, among which the cam mechanism includes the direct acting cam mechanism, the oscillating cam mechanism and the groove cam mechanism. The expansion analysis process of conversion mechanism, which can explain the six rules of divergence tree of matter-element: one object multi features, one feature multi objects, one feature multi values, one feature-element multi values, one value multi matter, one object one feature and multiple values in order.

The second is to combine extension innovation tools with research topics, promote graduates' understanding and application of extension innovative tools, which is helpful to further study the application of extension innovation tools. For example, students whose research topic is about green design then the extension innovation tools can be used to solve the problem of incompatible contradictions (such as the contradiction between interference fit and disassembly of 
bearings and shafts) in product recovery design process. Furthermore, the extension solution method of inconsistent contradiction problem is developed.

\section{STUDY ON THE CURRICULUM SYSTEM OF GRADUATE INNOVATION ABILITY BASED ON EXTENICS}

Through the analysis of difficulties existing in postgraduate innovative ability cultivation, we found that to build a curriculum system of graduate innovation education, three main problem should be solved: first is how to design the curriculum system and its goal; second is how to innovation practice; Third, how to provide a support of cultivation. According to these three questions, combining with the former analysis of difficulty in graduate innovation cultivation, "a goal of innovation ability, three systems, and one support "of" 131 " curriculum system for graduate student innovation ability is built, as shown in Fig. 1.

"One goal" refers to the cultivation goal of graduate innovation ability, including knowledge, quality and ability. The knowledge is embodied in the deep professional knowledge, broad knowledge, and the innovative method knowledge, etc.; Quality is reflected in the innovation consciousness (have consciousness of finding problem, asking questions, and actively solving the problem) and innovation personality (have the continuous exploration of curiosity, firm belief in self-confidence, indomitable enterprising spirit, inclusive open heart and responsibility of serving the society).

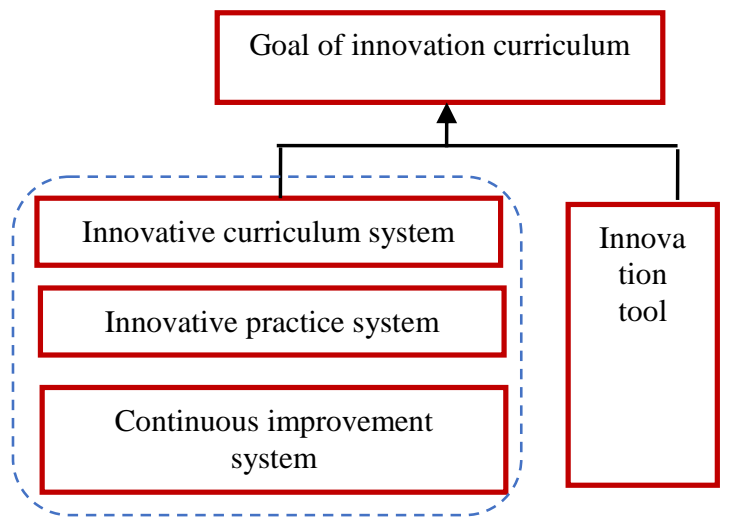

Fig. 1 The curriculum system of graduate students' innovative ability

Ability is reflected in innovative thinking ability (a comprehensive thinking ability to think with novel and unique angle of view and form new theories and methods under the guidance of the rational exploration) and innovative practice ability (take advanced approaches and technology to practice and explore and produce ability of new creating and innovating on the basis of finding problems, using existing information, combing innovative methods).

"Three systems" refers to the three supporting systems that are provided to achieve the goal of innovation ability. Specifically, it is the innovation curriculum system, innovation practice system and continuous improvement system.

Innovative curriculum system, as shown in Fig. 2, including innovation method course and combines the method of professional courses. Professional courses are referring to the degree course and core elective courses. Furthermore, the innovative curriculum system combines Extenics innovation tool with some examples of case, which can not only impart professional knowledge but also apply innovative approaches. The course of graduate innovation and entrepreneurship also includes innovative entrepreneurship curriculum, entrepreneurial opportunity identification course, business plan course (including enterprise organization, enterprise organization and management).

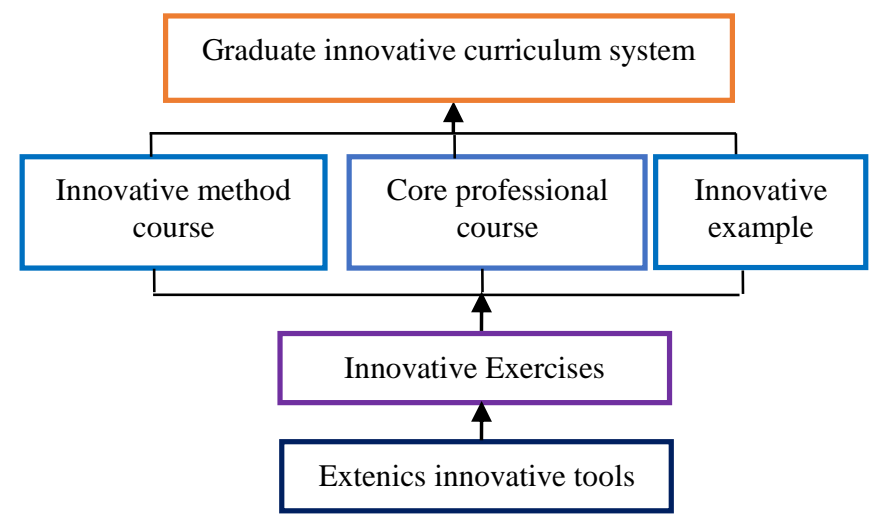

Fig. 2 The innovative curriculum system

Innovation practice system, as shown in Fig. 3, including innovation of course practice project and research project practice. The innovation curriculum practice is a project set up according to the need of Extenics innovation tools. The practice of scientific research project is the innovative practice (applying innovative approaches) of graduate students combining with their own research direction.

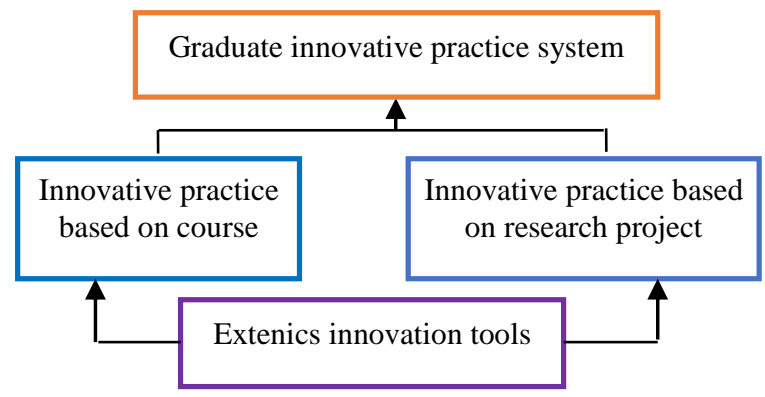

Fig. 3 The innovative practice system

The evaluation and improvement system, as shown in Fig.4, includes the evaluation of innovation courses, the evaluation of cultivation objectives and the continuous improvement mechanism. Evaluation of the achievement of innovative courses is based on the composite scores (including test scores and performance at ordinary times, course participation, etc.) to evaluate whether the course meet the requirements of its support training target index point (typically set to 0.65). Evaluation of the attainment of cultivation objectives is weighted synthesis on the basis of achievement evaluation of innovative courses and the value higher than the requirement (generally set up to be 0.65 ) means qualified. Continuous improvement mechanism build improved approach and apply it and then implement a new round of circular evaluation and improvement through finding 
reasons from the knowledge grasp, teaching design, classroom management, learning effectiveness.

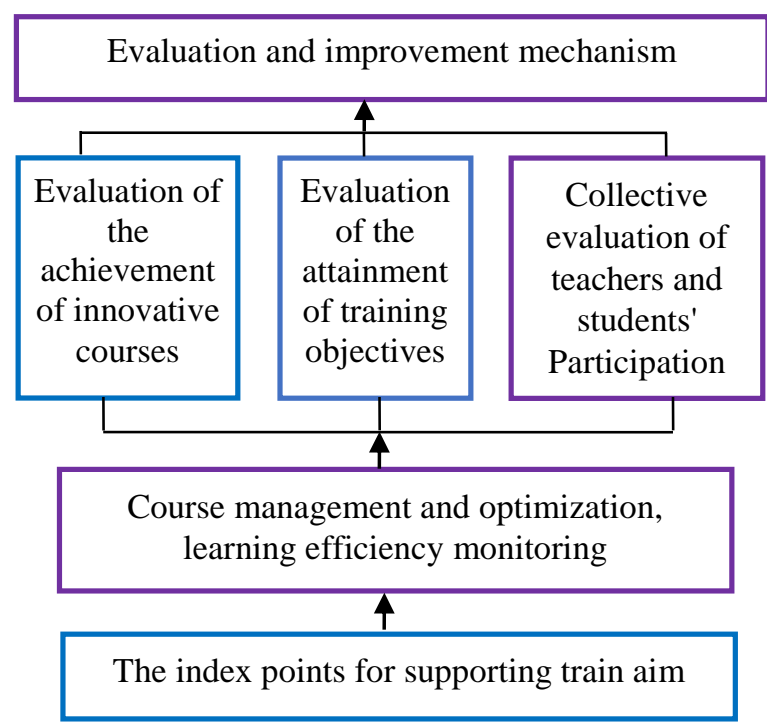

Fig. 4 The evaluation and improvement system

There is an interaction between innovative curriculum system, innovative practice system and continuous improvement system. Innovation is the foundation of the innovation ability cultivation system; system of innovative practice is an important means of innovation. Continuous improvement system provides innovative curriculum and innovative practice evaluation and improvement mechanisms, has the function of monitoring and supervision.

There are two reform measures that includes the integration of extension innovation tools and core courses, the integration of research teaching methods and students' main mode. The integration of Extenics innovation tools and professional core courses can solve the case solving problems of professional core courses according to the Extenics innovation process. This will help graduate students understand and master these two aspects of knowledge, but also make innovation methods appear repeatedly in learning process, increase graduate students' contact and application opportunities for innovative methods, and Strengthen its mastery of extension innovation tools.

The research-oriented teaching method enables students to study in near-real environment by creating problems situations, explanations, seminars and summaries so as to stimulate students' learning interest and innovation ability. The student speaking model will enhance students' pre-class preparation and increase the breadth and depth of their knowledge. Through the integration of the two elements, we let graduate students be the speaker using research teaching method, according to the speaker's content, design problem situation, knowledge interpretation, discussion and summary. The implementation trained many kinds of ability of graduate students, such as lecture design, expression, organization and innovation ability.
The learning results of postgraduate courses is based on the collective evaluation method that teachers and students participate in. In the course of innovation and entrepreneurship practice, students' mutual assessment, reply and the evaluation committee of teachers and students are adopted.

"One support" is Extenics theory. As an important original innovation method, Extenics innovation method is key role to the guidance of students' innovative design and the enhancement of innovation ability. When mechanical postgraduates are engaged in innovative design, they can expand their creativity by using Extenics innovation method and get innovative design ideas. In the process of innovation and entrepreneurship, it is possible to solve problems with Extenics innovation method and get a perfect solution. Therefore, the Extenics innovation method is an important support for postgraduates' innovation and entrepreneurship curriculum system.

Review the above-mentioned problems in the cultivation of postgraduates' innovative ability, we can find corresponding measures in this cultivation system, which also explains cultivation system can solve the problems existing in the current graduate student innovation ability cultivation.

\section{CONCLUSION}

The cultivation of graduate students' innovation ability plays an important role in the implementation of innovation driven development in our country. Based on the analysis of the difficulties existing in the curriculum system construction of graduate students' innovative ability, this paper establishes a curriculum system model of graduate students' innovative ability. The system gives detailed measures on cultivation objectives, curriculum system, practice system, evaluation and improvement system, and discusses two reform measures and role of Extenics innovation method.

\section{ACKNOWLEDGMENT}

This work was financially supported by Guangdong Higher Education Teaching Reform Project of Higher Education (Guangdong High Education Letter [2016] No.236412), Guangdong Graduate Education Innovation Project (Guangdong Teaching and Research Letter [2016] No. 392016JGXM_MS_50), Guangzhou teaching achievements cultivation project (Guangzhou Education [2017] 93), Guangzhou university innovation and entrepreneurship education project (201709k20), Guangdong province quality online course "innovation and invention" (Guangdong education high letter [2017]214). 


\section{REFERENCES}

[1] C.P. Hu, M.P. Liu, B.S. Ge. Innovation and entrepreneurship education among graduate students in Chinese universities Problems and countermeasures. Heilongjiang Researches on Higher Education, 2016, 2: $77-80$.

[2] K.W. Zhangi. Research on practices of entrepreneurship for engineering graduate student who based on the innovation and entrepreneurship education. Innovation and Entrepreneurship, 2016, 11: 44-48.

[3] J.F. Hu, Y. Jiang. Study on the construction of curriculum system of innovation and entrepreneurship education in universities. Innovation and Entrepreneurship Education, 2016, 7(4): 107-109.

[4] S.L. Li, G. Xiong, T.Y. Wu, et al. On curriculum system construction for postgraduates in innovation and entrepreneurship education. Journal of Graduate Education, 2017, 4: 45-50.

[5] F. Jiang, C.L. Zhang, Q.F. Wu, et al. Study on the Innovation Competency Model of Students with Mechanical Major. Advances in Computer Science Research, 2017, 70(5): 96-100.

[6] F. Jiang, C.L. Zhang, Y.J. Wang, et al. Study on the Thinking Expand Method in the Mechanism Theory Teaching. The Proceeding of the 11th International Conference on Computer Science \& Education, 2016.8: 877-882

[7] F. Jiang.TRIZ. Innovative application and innovative engineering education research [J]. Beijing Institute of Technology Press, 2013: 36.

[8] F. Jiang, P.H. Yang. Research on the fusion method of TRIZ theory and Extenics. Journal of Guangzhou University (Natural Science Edition), 2014, 13(6): 59-64.

[9] F. Jiang. Comparison between TRIZ and Extenics and research on fusion mechanism. Beijing Institute of Technology Press, 2015:87.

[10] F. Jiang, C.L. Zhang, Y.J. Wang. Construction of initiative practice ability cultivation system for mechanical major students. Research in Higher Education of Engineering, 2016(1): 187-192.

[11] F. Jiang, C.X. Ling. Design of injector used in the marine desalination equipment based on Extenics. Technology of Water Treatment, 2015, 41(12): 122-125.

[12] F. Jiang, W.Z. Fang, P.F. Yue, et al. Mechanical kinematic scheme design of packing lifting device based on ideal superiority evaluation method. Packaging Engineering, 2016, 37(14): 11-15.

[13] F. Jiang, Y.J. Wang, Z.M. Xiao, et al. Application of Extenics in the practical course of mechanical major. Experiment Science and Technology, 2013, 11(6): 20-23. 